\title{
Streptacidiphilus anmyonensis sp. nov., Streptacidiphilus rugosus sp. nov. and Streptacidiphilus melanogenes sp. nov., acidophilic actinobacteria isolated from Pinus soils
}

\author{
Sung-Heun Cho, Ji-Hye Han, Hye-Young Ko and Seung Bum Kim
}

Correspondence

Seung Bum Kim

sbk01@cnu.ac.kr

\author{
Department of Microbiology, School of Bioscience and Biotechnology, Chungnam National \\ University, 220 Gung-dong, Yuseong, Daejeon 305-764, Republic of Korea
}

Acidophilic actinobacteria with streptomycete-like features are common in terrestrial habitats such as acidic forest and mine-drainage soils, where they form a major constituent of the actinobacterial community (Williams et al., 1971; Khan \& Williams, 1975; Hagedorn, 1976; Goodfellow \& Dawson, 1978; Lonsdale, 1985; Seong, 1992; Cho et al., 2006). These actinobacteria are potential sources of commercially significant antifungal compounds and acidstable enzymes (Williams \& Khan, 1974; Williams \& Flowers, 1978) and are likely to have a major role in the decomposition of fungal biomass in acid litters and soils (Williams \& Robinson, 1981). It has been shown that acidophilic actinobacteria consistently form two distinct aggregate taxa (namely, the neutrotolerant acidophilic and strictly acidophilic cluster-groups) on the basis of numerical phenetic data (Khan \& Williams, 1975; Lonsdale, 1985;

The GenBank/EMBL/DDBJ accession numbers for the 16S rRNA gene sequences of strains $\mathrm{AM}-11^{\top}, \mathrm{AM}-16^{\top}$ and $\mathrm{SB}-\mathrm{B} 34^{\top}$ are D0904546, D0904547 and D0994689; those of other strains described in this work are given in Supplementary Fig. S1.

An extended neighbour-joining phylogenetic tree and whole-cell fatty acid profiles for strains $\mathrm{AM}-11^{\top}, \mathrm{AM}-16^{\top}$ and $\mathrm{SB}-\mathrm{B} 34^{\top}$ and recognized Streptacidiphilus species are available as supplementary data in the online version of this paper.
Seong et al., 1993) and genotypic data for the 16S rRNA gene (Kim et al., 2003, 2004; Xu et al., 2006). Streptacidiphili are aerobic, Gram-positive, acidophilic (i.e. optimal growth around $\mathrm{pH} 4.5$ ), chemo-organotrophic actinobacteria that form extensively branched substrate mycelium and aerial hyphae that differentiate into long chains of smooth-surfaced spores. The major chemotaxonomic features include the following: LL-diaminopimelic acid as the major diamino acid in the cell wall, galactose and rhamnose as the diagnostic sugars in whole-cell hydrolysates, diphosphatidylglycerol, phosphatidylethanolamine, phosphatidylinositol and phosphatidylinositol mannosides as the main polar lipids, hexahydrogenated and octahydrogenated menaquinones [MK-9 $\left(\mathrm{H}_{8}\right)$ ] with nine isoprene units as the major respiratory quinones and a mixture of saturated, iso- and anteiso-branched fatty acids (Lonsdale, 1985; Seong, 1992). Strict acidophiles were found to constitute a novel genus within the family Streptomycetaceae, and three species, Streptacidiphilus albus, Streptacidiphilus carbonis and Streptacidiphilus neutrinimicus were initially described (Kim et al., 2003). Two additional species, Streptacidiphilus jiangxiensis (Huang et al., 2004) and Streptacidiphilus oryzae (Wang et al., 2006), were described subsequently. 
Following a previous report of the isolation of acidophilic actinobacteria from soils associated with Pinus thunbergii (Cho et al., 2006), the taxonomic status of representative isolates belonging to the genus Streptacidiphilus was examined in this study by using a polyphasic approach.

All of the strains were maintained and examined on agar media adjusted to $\mathrm{pH}$ 4.5-5.0. They were kept on acidified modified Bennett's agar and starch-casein agar plates (Seong, 1992) at room temperature and as suspensions of mycelial fragments and spores in glycerol $(20 \%, \mathrm{v} / \mathrm{v})$. Biomass for the diaminopimelic acid, fatty acid, menaquinone and molecular systematic analyses was obtained from shake-flask cultures and test tubes containing modified Bennett's broth ( $\mathrm{pH}$ 5.0) grown at $30{ }^{\circ} \mathrm{C}$ for 7 days. Biomass for chemical and molecular systematic studies was washed twice in distilled water and then freeze-dried; biomass for preservation was stored at -20 and $-70{ }^{\circ} \mathrm{C}$.

The strains were inoculated onto acidified modified Bennett's and acidified inorganic salts-starch (ISP 4 medium; Shirling \& Gottlieb, 1966) agar plates and incubated at $30{ }^{\circ} \mathrm{C}$ for 14 days. The plates were examined visually to determine the colour of the aerial spore mass, substrate mycelial pigments and soluble pigments. Yeast extract-malt extract (ISP 2 medium; Shirling \& Gottlieb, 1966) agar was used to determine the production of soluble pigments. Spore-chain morphology and spore-surface ornamentation were examined using scanning electron microscopy, as described previously (O'Donnell et al., 1993). Phenotypic properties of the strains were examined using established procedures (Seong et al., 1993; Williams et al., 1983), but with acidified media.

Isoprenoid quinones and diaminopimelic acid were investigated using reversed-phase HPLC procedures as described by Komagata \& Suzuki (1987) and El-Waziry et al. (1996), respectively. Fatty acids were extracted, methylated and analysed by GC using the standard Microbial Identification System (MIDI) (Sasser, 1990; Kämpfer \& Kroppenstedt, 1996).

Isolation of chromosomal DNA, PCR amplification and direct sequencing of the PCR products were carried out as described previously (Park et al., 2005). The resultant $16 \mathrm{~S}$ rRNA gene sequences were aligned together with corresponding sequences from representative species of the genera Kitasatospora, Streptacidiphilus and Streptomyces by using the PHYDIT program (version 3.1; available at http://plaza.snu.ac.kr/ jchun/phydit/). Phylogenetic trees were inferred using the Fitch-Margoliash, maximumlikelihood, maximum-parsimony and neighbour-joining methods according to previously described procedures (Kim et al., 2003; Park et al., 2006).

Levels of DNA-DNA relatedness were determined using the procedure described by Cho \& Giovannoni (2004). The hybridization temperature was $55{ }^{\circ} \mathrm{C}$. Densitometric analyses were carried out using a Personal Densitometer with ImageQuant imaging software (Bio-Rad).
All of the novel isolates were Gram-positive, aerobic, acidophilic actinobacteria. All formed extensively branched substrate mycelia and aerial hyphae that differentiated into long, straight to flexuous chains of smooth-surfaced spores. Brown or cream-coloured colonies carrying moderate to abundant white or greyish-white aerial hyphae were formed on acidified oatmeal agar, ISP 4 agar, ISP 2 agar and modified Bennett's agar.

The major diamino acid of the peptidoglycan was LLdiaminopimelic acid, although minor amounts of the meso isomer were detected. Representative isolates $\mathrm{AM}-11^{\mathrm{T}}$, $\mathrm{AM}-16^{\mathrm{T}}$ and $\mathrm{SB}-\mathrm{B} 34^{\mathrm{T}}$ contained 13 -methyltetradecanoic acid (iso- $\mathrm{C}_{15: 0} ; 15-20 \%$ of the total fatty acid composition), 12-methyltetradecanoic acid (anteiso- $\mathrm{C}_{15: 0} ; 7-$ $15 \%$ ), 14-methylpentadecanoic acid (iso- $\mathrm{C}_{16: 0} ; 15-25 \%$ ), n-hexadecanoic acid $\left(\mathrm{C}_{16: 0} ; 15-16 \%\right), 15$-methylhexadecanoic acid (iso- $\mathrm{C}_{17: 0} ; 3-7 \%$ ) and 14-methylhexadecanoic acid (anteiso- $\mathrm{C}_{17: 0} ; 4-7 \%$ ) (see Supplementary Table S1, available in IJSEM Online). All of the three strains contained hexahydrogenated and octahydrogenated menaquinones with nine isoprene units [MK-9 $\left(\mathrm{H}_{6}\right)$ and MK$9\left(\mathrm{H}_{8}\right)$, comprising $18-24$ and $59-69 \%$ of the total, respectively] as the predominant isoprenologues.

From the phylogenetic analysis of 1358 nucleotide positions from the 16S rRNA gene sequences, the isolates formed three distinctive phylogenetic lines within the taxonomic variation encompassed by the genus Streptacidiphilus (Fig. 1). The expanded phylogenetic tree including all 22 isolates tested also showed three independent phyloclusters (Supplementary Fig. S1). It was notable that the isolates from the Anmyeon area (AM prefixes) were split into two separate phyloclusters, whereas isolates from the Sambong area (SB prefixes) formed an independent phylocluster. The strains belonging to each phylocluster shared the same morphological and cultural characteristics.

The DNA-DNA relatedness data for the representative strains and the type strain of $S$. jiangxiensis confirmed that all of the taxa could be clearly separated from one another (Table 1). Strains AM- $16^{\mathrm{T}}$ and S. jiangxiensis $33214^{\mathrm{T}}$ shared $34 \%$ DNA-DNA relatedness. Strain SB-B $34^{\mathrm{T}}$ exhibited $30 \%$ DNA-DNA relatedness with respect to $S$. jiangxiensis $33214^{\mathrm{T}}, 42 \%$ with respect to strain $\mathrm{AM}-11^{\mathrm{T}}$ and $23 \%$ with respect to strain $\mathrm{AM}-16^{\mathrm{T}}$. No obvious correlation was observed between the 16S rRNA gene sequence similarity and DNA-DNA relatedness data (Table 1).

The representative isolates could be separated from other Streptacidiphilus species with validly published names and also from one another by using a combination of phenotypic tests (Table 2). It is evident from the results of the polyphasic study, including the phenotypic data, the diamino acid present in the peptidoglycan, the fatty acid profiles, the DNA-DNA hybridization data and the phylogenetic results for the 16S rRNA gene, that each of the three novel phyloclusters of Streptacidiphilus should be recognized as an independent species. The names proposed 


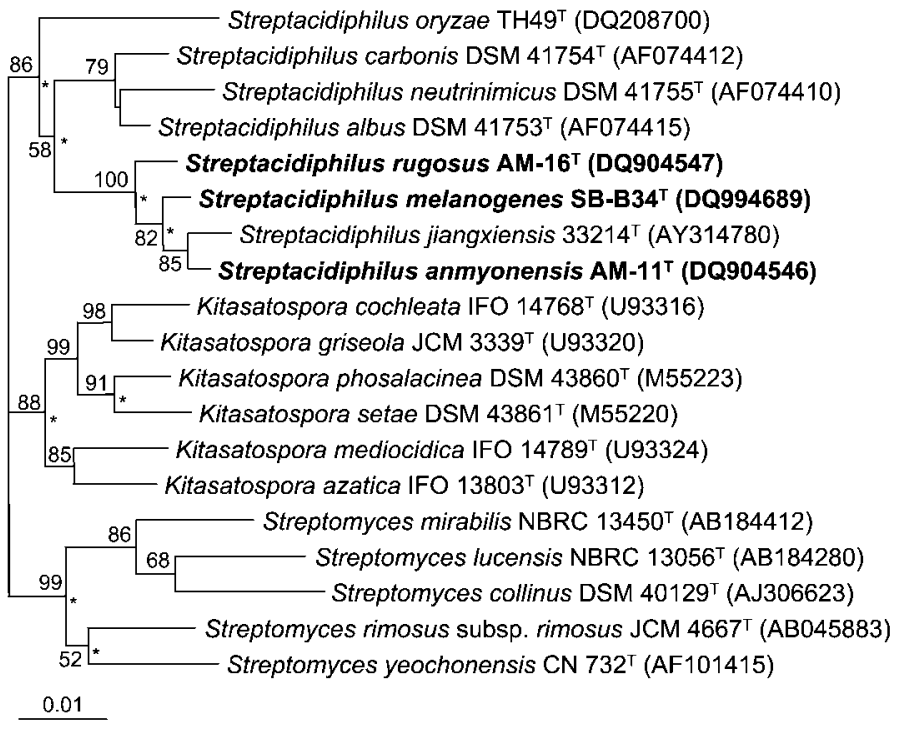

Fig. 1. Neighbour-joining phylogenetic tree (Saitou \& Nei, 1987), based on almostcomplete 16S rRNA gene sequences, showing the relationships between the isolates and representatives of the genus Streptacidiphilus. Asterisks indicate branches that were also recovered using the Fitch-Margoliash, maximum-likelihood and maximum-parsimony methods. Numbers at nodes indicate bootstrap percentages (based on neighbour-joining analysis of 1000 resampled datasets using Jukes-Cantor distances); only values over $50 \%$ are given. Bar, 0.01 substitutions per nucleotide position. An extended version of this tree, including all 22 novel isolates, is available as Supplementary Fig. S1. for the three novel species are Streptacidiphilus anmyonensis sp. nov. (type strain AM-11 $1^{\mathrm{T}}$ ), Streptacidiphilus rugosus sp. nov. (type strain AM-16 ${ }^{\mathrm{T}}$ ) and Streptacidiphilus melanogenes sp. nov. (type strain SB-34 ${ }^{\mathrm{T}}$ ).

\section{Description of Streptacidiphilus anmyonensis sp. nov.}

Streptacidiphilus anmyonensis (an.myon.en'sis. N.L. masc. adj. anmyonensis of Anmyon, where the first strains were isolated).

Forms cream-coloured colonies that carry moderate to abundant, white to greyish-white aerial hyphae on acidified oatmeal, ISP 4, ISP 2 and modified Bennett's agar plates. Substrate mycelium is brownish grey or brown on acidified oatmeal agar and ISP 2 agar, but cream on ISP 4 agar and modified Bennett's agar. Aerial hyphae differentiate into long flexuous chains of spores $(0.6 \times 0.9 \mu \mathrm{m})$; the spore surface is smooth. Soluble pigments are not produced on any of the above-mentioned media. Growth occurs at $\mathrm{pH} 3.0-8.0$ and $28-35^{\circ} \mathrm{C}$. Starch and Tween 80 are

Table 1. DNA-DNA relatedness and $16 \mathrm{~S}$ rRNA gene sequence similarity among strains $A M-11^{\top}, A M-16^{\top}$, SB$B 34^{\top}$ and S. jiangxiensis $33214^{\top}$

Values above the diagonal are 16S rRNA gene sequence similarity values (\%). Values below the diagonal are mean percentages from three reciprocal DNA-DNA hybridization reactions.

\begin{tabular}{|lcccc|}
\hline Strain & 33214 $^{\mathbf{T}}$ & AM-11 $^{\mathbf{T}}$ & AM-16 $^{\mathbf{T}}$ & SB-B34 $^{\mathbf{T}}$ \\
\hline $33214^{\mathrm{T}}$ & - & 99.3 & 98.1 & 98.8 \\
$\mathrm{AM}^{\mathrm{T}} 11^{\mathrm{T}}$ & 35 & - & 98.5 & 99.3 \\
$\mathrm{AM}^{\mathrm{T}} 6^{\mathrm{T}}$ & 34 & 29 & - & 99.2 \\
SB-B34 $^{\mathrm{T}}$ & 30 & 42 & 28 & - \\
\hline
\end{tabular}

degraded, but xanthine and Tweens 20 and 40 are not. Glycerol, D-gluconic acid, $\mathrm{D}(+)$-glucosamine hydrochloride, myo-inositol, melibiose, D-sorbitol, sucrose and $\mathrm{D}(+)$-xylose (each at $1 \%, \mathrm{w} / \mathrm{v}$ ) and L-arginine (at $0.1 \%$, $\mathrm{w} / \mathrm{v}$ ) are used as sole carbon sources for energy and growth, but L-aspartic acid and sodium oxalate (each at $0.1 \%, \mathrm{w} / \mathrm{v}$ ) are not. L-Isoleucine is used as a sole nitrogen source. Chemotaxonomic properties are typical of those for the genus Streptacidiphilus. The major fatty acids are iso- $\mathrm{C}_{15: 0}$ (18.4\% of the total fatty acid composition), anteiso- $\mathrm{C}_{15: 0}$ $(11.4 \%)$, iso- $\mathrm{C}_{16: 0}(19.1 \%), \mathrm{C}_{16: 0}(14.7 \%)$, iso- $\mathrm{C}_{17: 0}$ $(7.4 \%)$ and anteiso- $\mathrm{C}_{17: 0}(7.5 \%)$. Contains hexahydrogenated and octahydrogenated menaquinones with nine isoprene units $\left[\mathrm{MK}-9\left(\mathrm{H}_{6}\right)\right.$ and $\mathrm{MK}-9\left(\mathrm{H}_{8}\right) ; 24.1$ and $55.8 \%$ of the total, respectively] as the predominant isoprenologues. The diamino acid of the peptidoglycan is LL-diaminopimelic acid ( $89 \%$ of the total diaminopimelic acid composition), although a minor amount of the meso isomer $(11 \%)$ is also detected.

The species currently includes the type strain $A M-11^{\mathrm{T}}$ $\left(=\mathrm{NBRC} 103185^{\mathrm{T}}=\mathrm{KCTC} 19278^{\mathrm{T}}\right.$ ) and strains AM-02, AM-06, AM-08, AM-10, AM-17, AM-18, AM-23, AM-24, AM-25 and AM-30, isolated from Pinus-associated soils from Anmyeon, near the coastal areas of Tae-An, Chungnam, Republic of Korea (Cho et al., 2006).

\section{Description of Streptacidiphilus rugosus sp. nov.}

Streptacidiphilus rugosus (ru.go'sus. L. masc. adj. rugosus wrinkled).

Forms cream-coloured, rugose colonies that carry moderate to abundant white aerial hyphae on acidified oatmeal, ISP 4, ISP 2 and modified Bennett's agar plates. Substrate mycelium is cream on acidified ISP 4, ISP 2 and modified Bennett's agars, but yellowish brown or brown on oatmeal 
Table 2. Phenotypic properties that serve to distinguish strains $A M-11^{\top}, A M-16^{\top}$ and $S B-B 34^{\top}$ from type strains of Streptacidiphilus species with validly published names

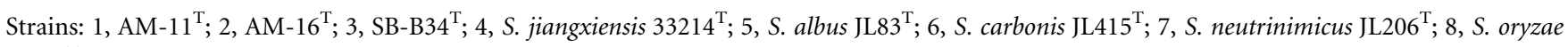
$\mathrm{TH} 49^{\mathrm{T}}$. All strains were positive for the utilization of glycerol and sucrose and also for growth at $\mathrm{pH} 4,5$ and 6.

\begin{tabular}{|c|c|c|c|c|c|c|c|c|}
\hline Characteristic & 1 & 2 & 3 & 4 & 5 & 6 & 7 & 8 \\
\hline \multicolumn{9}{|l|}{ Degradation of: } \\
\hline Starch & + & + & + & + & + & + & + & - \\
\hline Tween 40 & - & - & + & - & + & + & - & + \\
\hline Tween 80 & + & + & + & - & - & - & - & + \\
\hline Xanthine & - & - & + & + & + & + & - & - \\
\hline D-Gluconic acid & + & + & + & + & - & + & - & + \\
\hline D-Glucosamine hydrochloride & + & - & + & + & + & + & + & + \\
\hline myo-Inositol & + & + & + & + & - & + & + & + \\
\hline Melibiose & + & - & + & + & + & + & + & + \\
\hline D-Sorbitol & + & + & + & + & - & + & + & + \\
\hline D-Xylose & + & - & + & - & - & + & + & + \\
\hline Growth on L-isoleucine $(0.1 \%, w / v)$ as sole nitrogen source & + & + & + & + & - & + & + & + \\
\hline Growth at $\mathrm{pH} 3$ & + & - & + & - & + & + & - & + \\
\hline
\end{tabular}

agar. Aerial hyphae differentiate into long flexuous chains of spores $(0.5 \times 1.2 \mu \mathrm{m})$; the spore surface is smooth. Soluble pigments are not produced on any of the abovementioned media. Growth occurs at $\mathrm{pH} 3.0-8.0$ and 28$35{ }^{\circ} \mathrm{C}$. Starch and Tween 80 are degraded, but xanthine and Tweens 20 and 40 are not. Glycerol, D-gluconic acid, myoinositol, D-sorbitol and sucrose (each at $1 \%$, w/v), Larginine and sodium oxalate (each at $0.1 \%, \mathrm{w} / \mathrm{v}$ ) are used as sole carbon sources for energy and growth, but $\mathrm{D}(+)$ glucosamine hydrochloride, melibiose and $\mathrm{D}(+)$-xylose (each at $1 \%, w / v)$ and L-aspartic acid (at $0.1 \%$, w/v) are not. L-Isoleucine is used as a sole nitrogen source. Chemotaxonomic properties are typical of those for the genus Streptacidiphilus. The major fatty acids are iso- $\mathrm{C}_{15: 0}$ (15\% of the total fatty acid composition), anteiso- $\mathrm{C}_{15: 0}$ (14.9\%), iso- $\mathrm{C}_{16: 0}(25.4 \%), \mathrm{n}-\mathrm{C}_{16: 0}(15.6 \%)$, iso- $\mathrm{C}_{17: 0}$ $(3.0 \%)$ and anteiso- $\mathrm{C}_{17: 0}(4.7 \%)$. Contains hexahydrogenated and octahydrogenated menaquinones with nine isoprene units [MK-9 $\left(\mathrm{H}_{6}\right)$ and MK- $9\left(\mathrm{H}_{8}\right) ; 19.8$ and $59.6 \%$ of the total, respectively] as the predominant isoprenologues. The diamino acid of the peptidoglycan is LL-diaminopimelic acid ( $94 \%$ of the total diaminopimelic acid composition), although a minor amount of the meso isomer $(6 \%)$ is also detected.

The species currently includes the type strain $\mathrm{AM}-16^{\mathrm{T}}$ $\left(\right.$ NBRC $103186^{\mathrm{T}}=$ KCTC $\left.19279^{\mathrm{T}}\right)$ and strains AM-20, AM21, AM-22, AM-26, AM-27, AM-28 and AM-29, isolated from Pinus-associated soils from Anmyeon, near the coastal areas of Tae-An, Chungnam, Republic of Korea.

\section{Description of Streptacidiphilus melanogenes sp. nov.}

Streptacidiphilus melanogenes [me.la.no'gen.es. Gr. n. melas -anos black; Gr. v. suff. -genes producing; N.L. part. adj. melanogenes producing black (pigment)].

Forms cream-coloured colonies that carry moderate to abundant white aerial hyphae on acidified oatmeal, ISP 4, ISP 2 and modified Bennett's agar plates. Substrate mycelium is brownish grey or brown on acidified ISP 4 agar and ISP 2 agar, but cream on oatmeal agar and modified Bennett's agar. Aerial hyphae differentiate into long flexuous chains of spores $(0.6 \times 1.0 \mu \mathrm{m})$; the spore surface is smooth. Brownish-grey diffusible pigments are formed on acidified oatmeal agar and ISP 2 agar. Soluble pigments are not produced on ISP 4 agar or modified Bennett's agar. Growth occurs at $\mathrm{pH} 3.0-8.0$ and $28-35{ }^{\circ} \mathrm{C}$. Starch, Tweens 40 and 80 and xanthine are degraded, but Tween 20 is not. Glycerol, D-gluconic acid, D(+)glucosamine hydrochloride, myo-inositol, melibiose, Dsorbitol, sucrose and $\mathrm{D}(+)$-xylose (each at $1 \%, \mathrm{w} / \mathrm{v}$ ), L-arginine and sodium oxalate (each at $0.1 \%, \mathrm{w} / \mathrm{v}$ ) are used as sole carbon sources for energy and growth, but Laspartic acid (at $0.1 \%, \mathrm{w} / \mathrm{v}$ ) is not. $\mathrm{L}$-Isoleucine is used as a sole nitrogen source. Chemotaxonomic properties are typical of those for the genus Streptacidiphilus. The major fatty acids are iso- $\mathrm{C}_{15: 0}(20.4 \%$ of the total fatty acid composition), anteiso- $\mathrm{C}_{15: 0}(6.7 \%)$, iso- $\mathrm{C}_{16: 0}(14.7 \%), \mathrm{n}$ $\mathrm{C}_{16: 0}(15.7 \%)$, iso- $\mathrm{C}_{17: 0}(7.3 \%)$ and anteiso- $\mathrm{C}_{17: 0}$ $(3.8 \%)$. Contains hexahydrogenated and octahydrogenated 
menaquinones with nine isoprene units $\left[\mathrm{MK}-9\left(\mathrm{H}_{6}\right)\right.$ and MK-9 $\left(\mathrm{H}_{8}\right) ; 18.1$ and $68.6 \%$ of the total, respectively] as the predominant isoprenologues. The diamino acid of the peptidoglycan is LL-diaminopimelic acid (100\% of the total diaminopimelic acid composition).

The species currently includes the type strain $\mathrm{SB}-\mathrm{B} 34^{\mathrm{T}}$ $\left(=\mathrm{NBRC} 103184^{\mathrm{T}}=\mathrm{KCTC} 19280^{\mathrm{T}}\right)$ and strains SB-B33 and SB-B35, isolated from Pinus-associated soils from Sambong, near the coastal areas of Tae-An, Chungnam, Republic of Korea.

\section{Acknowledgements}

This work was supported by a Korea Science and Engineering Foundation (KOSEF) grant funded by the Government of Korea (MOST) (R01-2007-000-21120-0). S.-H. C. and J.-H. H. acknowledge support from the Brain Korea 21 program, and H.-Y. K. acknowledges support from the NURI program sponsored by the Ministry of Education.

\section{References}

Cho, J. C. \& Giovannoni, S. J. (2004). Oceanicola granulosus gen. nov., sp. nov. and Oceanicola batsensis sp. nov., poly- $\beta$-hydroxybutyrateproducing marine bacteria in the order 'Rhodobacterales'. Int J Syst Evol Microbiol 54, 1129-1136.

Cho, S. H., Han, J. H., Seong, C. N. \& Kim, S. B. (2006). Phylogenetic diversity of acidophilic sporoactinobacteria isolated from various soils. J Microbiol 44, 600-606.

El-Waziry, A. M., Tomita, Y., Ling, J. R. \& Onodera, R. (1996). Measurement of total and separate stereoisomers of diaminopimelic acid in rumen bacteria by high-performance liquid chromatography. J Chromatogr B Biomed Appl 677, 53-59.

Goodfellow, M. \& Dawson, D. (1978). Qualitative and quantitative studies of bacteria colonizing Picea sitchensis litter. Soil Biol Biochem 10, 303-307.

Hagedorn, C. (1976). Influences of soil acidity on Streptomyces populations inhabiting forest soils. Appl Environ Microbiol 32, 368-375.

Huang, Y., Cui, Q., Wang, L., Rodriguez, C., Quintana, E., Goodfellow, M. \& Liu, Z. (2004). Streptacidiphilus jiangxiensis sp. nov., a novel actinomycete isolated from acidic rhizosphere soil in China. Antonie van Leeuwenhoek 86, 159-165.

Kämpfer, P. \& Kroppenstedt, R. M. (1996). Numerical analysis of fatty acid patterns of coryneform bacteria and related taxa. Can J Microbiol 42, 989-1005.

Khan, M. R. \& Williams, S. T. (1975). Studies on the ecology of actinomycetes in soil. VIII. Distribution and characteristics of acidophilic actinomycetes. Soil Biol Biochem 7, 345-348.

Kim, S. B., Lonsdale, J., Seong, C. N. \& Goodfellow, M. (2003). Streptacidiphilus gen. nov., acidophilic actinomycetes with wall chemotype I and emendation of the family Streptomycetaceae (Waksman and Henrici $1943^{\mathrm{AL}}$ ) emend. Rainey (1977). Antonie van Leeuwenhoek 83, 107-116.
Kim, S. B., Seong, C. N., Jeon, S. J., Bae, K. S. \& Goodfellow, M. (2004). Taxonomic study of neutrotolerant acidophilic actinomycetes isolated from soil and description of Streptomyces yeochonensis sp. nov. Int J Syst Evol Microbiol 54, 211-214.

Komagata, K. \& Suzuki, K. (1987). Lipid and cell-wall analysis in bacterial systematics. Methods Microbiol 19, 161-207.

Lonsdale, J. T. (1985). Aspects of the biology of acidophilic actinomycetes. $\mathrm{PhD}$ thesis, University of Newcastle, Newcastle, UK.

O'Donnell, A. G., Falconer, C., Goodfellow, M., Ward, A. C. \& Williams, E. (1993). Biosystematics and diversity amongst novel carboxydotrophic actinomycetes. Antonie van Leeuwenhoek 64, 325-340.

Park, M. S., Jung, S. R., Lee, M. S., Kim, K. O., Do, J. O., Lee, K. H., Kim, S. B. \& Bae, K. S. (2005). Isolation and characterization of bacteria associated with two sand dune plant species, Calystegia soldanella and Elymus mollis. J Microbiol 43, 219-227.

Park, M. S., Jung, S. R., Lee, K. H., Lee, M. S., Do, J. O., Kim, S. B. \& Bae, K. S. (2006). Chryseobacterium soldanellicola sp. nov. and Chryseobacterium taeanense sp. nov., isolated from roots of sand-dune plants. Int J Syst Evol Microbiol 56, 433-438.

Saitou, N. \& Nei, M. (1987). The neighbor-joining method: a new method for reconstructing phylogenetic trees. Mol Biol Evol 4, 406-425.

Sasser, M. (1990). Identification of bacteria by gas chromatography of cellular fatty acids, MIDI Technical Note 101. Newark, DE: MIDI Inc.

Seong, C. N. (1992). Numerical taxonomy of acidophilic and neutrotolerant actinomycetes isolated from acid soil in Korea. $\mathrm{PhD}$ thesis, Seoul National University, Seoul, Republic of Korea.

Seong, C. N., Goodfellow, M., Ward, A. C. \& Hah, Y. C. (1993). Numerical classification of acidophilic actinomycetes isolated from acid soil in Korea. J Microbiol 31, 355-363.

Shirling, E. B. \& Gottlieb, D. (1966). Methods for characterization of Streptomyces species. Int J Syst Bacteriol 16, 313-340.

Wang, L., Huang, Y., Liu, Z., Goodfellow, M. \& Rodriguez, C. (2006). Streptacidiphilus oryzae sp. nov., an actinomycete isolated from ricefield soil in Thailand. Int J Syst Evol Microbiol 56, 1257-1261.

Williams, S. T. \& Flowers, T. H. (1978). The influence of $\mathrm{pH}$ on starch hydrolysis by neutrophilic and acidophilic actinomycetes. Microbios 20, 99-106.

Williams, S. T. \& Khan, M. R. (1974). Antibiotics - a soil microbiologist's viewpoint. Postepy Hig Med Dosw 28, 395-408.

Williams, S. T. \& Robinson, C. S. (1981). The role of streptomycetes in decomposition of chitin in acidic soils. J Gen Microbiol 127, 55-63.

Williams, S. T., Davies, F. L., Mayfield, C. I. \& Khan, M. R. (1971). Studies on the ecology of actinomycetes in soil. II. The $\mathrm{pH}$ requirements of streptomycetes from two acid soils. Soil Biol Biochem 3, 187-195.

Williams, S. T., Goodfellow, M., Alderson, G., Wellington, E. M. H., Sneath, P. H. A. \& Sackin, M. J. (1983). Numerical classification of Streptomyces and related genera. J Gen Microbiol 129, 1743-1813.

Xu, C., Wang, L., Cui, Q., Huang, Y., Liu, Z., Zheng, G. \& Goodfellow, M. (2006). Neutrotolerant acidophilic Streptomyces species isolated from acidic soils in China: Streptomyces guanduensis sp. nov., Streptomyces paucisporeus sp. nov., Streptomyces rubidus sp. nov. and Streptomyces yanglinensis sp. nov. Int J Syst Evol Microbiol 56, 1109-1115. 